\title{
Aragonese Language
}

National Cancer Institute

\section{Source}

National Cancer Institute. Aragonese Language. NCI Thesaurus. Code C153835.

A Romance language spoken in several dialects by people in the Pyrenees valleys of Aragon Spain. 